\title{
Examining factors affecting beginning teachers' transfer of learning of ICT-enhanced learning activities in their teaching practice
}

\author{
Douglas D. Agyei \\ University of Cape Coast, Ghana \\ Joke Voogt \\ University of Amsterdam, Netherlands
}

\begin{abstract}
This study examined 100 beginning teachers' transfer of learning when utilising Information Communication Technology-enhanced activity-based learning activities. The beginning teachers had participated in a professional development program that was characterised by 'learning technology by collaborative design' in their final year of their pre-service preparation program. Transfer of learning was proposed as characteristic of (i) the professional development program, (ii) beginning teachers and (iii) school environment. Beginning teachers held positive views about active learning and ICT use developed during the professional development program, which seemed the strongest predictor in transfer of their learning. The study also showed that a significant amount of explained differences in the level of transfer of ICT-enhanced activity-based learning innovation could be attributed to range of factors across individual beginning teachers and school environment characteristics. Implications of these findings are discussed.
\end{abstract}

\section{Introduction}

Formal training typically involves learning new knowledge, skills and attitudes in one environment (the training situation) that can be applied or used in another environment (the performance situation) (Goldstein \& Ford, 2002). However, several studies have shown that a common experience is that learning from a formal training program is often not or in a limited way applied on the job (e.g. Yamnill \& McLean, 2001; Saks, 2002). Since Baldwin and Ford's (1988) highly recognized review of the "transfer problem" in training research, an outpouring of conceptual and research-based suggestions have focused on how to lessen the gap between learning and sustained workplace performance (Yamnill \& McLean, 2001; Goldstein \& Ford, 2002; Burke \& Hutchins, 2007). Baldwin and Ford (1988) define positive transfer of training "as the degree to which trainees effectively apply the knowledge, skills and attitudes gained in a training context to the job" (p. 63). To be able to bridge the gap between learning and sustained workplace performance, it is important to understand the dynamics of transfer in order to look for ways to minimise transfer losses while improving the yield from any training program. Baldwin and Ford (1988) identified a taxonomy of major conceptual factors influencing transfer. They divided these factors into three groups of characteristics which directly or indirectly influence trainees' learning and the transfer of training: trainee characteristics, training characteristics, and work environment characteristics. Trainee characteristics refer to internal factors (e.g. ability, personality, and motivation) whereas training characteristics involve training design factors (e.g. principles of learning, sequencing, and training content). Baldwin and Ford referred to work environment characteristics as external factors which directly and indirectly affect trainees' learning and the transfer of training. While the question of transferability of training has been present in various disciplines, there is no much evidence of comprehensive transfer studies in teacher education involving the transfer of learning of pre-service teachers. The purpose of this study is to attain understanding of factors that influence newly trained mathematics teachers' transfer of Information Communication Technology-enhanced activity-based training which they received during their pre-service education.

\section{“Learning Technology by Collaborative Design"}

This transfer study grew out of a program of research to introduce Information Communication Technology (ICT) as a tool to improve teaching and learning of mathematics in pre-service teacher education in Ghana. In two iterative studies (in 2009 and 2010), a professional development program was designed to prepare final year pre-service teachers to integrate ICT in teaching mathematics in a teacher 
education institute (Agyei, 2012; Agyei \& Voogt, 2011). In early 2011, the approach was applied into a regular mathematics-specific instructional technology course of the teacher education institute (Agyei, 2012). The pre-service teachers involved in the arrangements were able to develop and demonstrate their competencies adequately in designing and enacting ICT-enhanced activity-based mathematics lessons as a result of the intervention in the three studies. Approximately six, eighteen, and twenty-eight months after the third, second and first arrangements respectively, the pre-service mathematics teachers (here after referred to as beginning teachers) had been posted into various senior high schools and were pursuing their careers as mathematics teachers.

The intervention (or professional development arrangement) adopted the "Learning Technology by Collaborative Design" (LTCD) (Koehler \& Mishra, 2005) approach to provide opportunity for beginning teachers to develop their competencies in ICT integration through collaborative design and enactment of ICT-based curriculum materials. The ICT application employed in the arrangements was a spreadsheet, because it is readily available on most computers and relevant for developing mathematics beginning teachers' integration competencies. Activity Based Learning (ABL) was applied as a pedagogical environment for use of spreadsheet. $\mathrm{ABL}$ assumes that students are actively involved in their learning process. It was envisaged that the combination of a specific pedagogy (ABL) and a specific technology (spreadsheets) would encourage the beginning teachers to apply their knowledge and skills in designing and enacting ABL lessons by employing a mix of direct instruction and hands-on activity to guide students through activities with spreadsheets to enhance student learning. The first eight weeks of the 14week professional development program required beginning teachers to attend one 2 hour lecture and one 2 hour laboratory session per week. The lectures were meant to update the beginning teachers by providing them with theoretical foundation/concepts (e.g. collaborative teacher design, ABL and other pedagogical tasks). Laboratory sessions included small group tasks in which design teams worked on their assignments and projects. Teams, however, had informal meetings and interactions intermittently to enable them complete their tasks. Exemplary materials of spreadsheet-based demonstration lesson models (designed by the researcher) were a necessary component of the professional development arrangement. Based on their experiences, beginning teachers (in teams) were challenged to select mathematics topics suitable for teaching with spreadsheets, and to make use of the affordances of the technology to design learning activities that foster higher order thinking in developing and modeling their own mathematics lessons. Beginning teachers enacted their developed lessons in a micro or peer teaching context and in some cases in real classroom situations at the secondary schools during the last six weeks of the program. Each lesson document comprised a teachers' guide to help set up the environment, a plan for lesson implementation and a student worksheet which promoted hands-on activities during the lesson implementation. The lessons were taught in a classroom with a computer and a LCD projector. The researcher's role was demonstrative during the lecture sessions and consultative during lab sessions.

\section{Factors influencing transfer of teacher learning}

If research-based ICT related innovations are not transferrable, to utilise skills and knowledge learned in beginning preparation setting to a real world work situation, then there is little expectation that investment and efforts made during the preparation will have a deep and lasting effect on education. Of much relevance to this study was the potential of transfer of the ICT-enhanced activity-based learning in the teachers' professional and teaching practice. In this paper, Baldwin and Ford's (1988) model was used to analyse the beginning teachers' transfer of learning. Based on the model, characteristics of the professional development program (i.e. LTCD), referred to by Baldwin and Ford as "training characteristics", was considered one out of the three factors influencing transfer of learning. Burke and Hutchins (2007) also referred to it as intervention design and delivery and indicated that it is an important factor that influences transfer directly or indirectly. As reported earlier, LTCD in this study was characterised by:

- Use of design teams to develop worksheets, spreadsheet techniques and lesson plans

- Use of exemplary materials (or resources from internet)

- Support from facilitator

- Learning by doing (by exploring spreadsheet techniques and activities)

- Enactment of lesson plans in microteaching or classroom settings (cf. Agyei, 2012; Agyei \& Voogt, 2011). 
Mumtaz (2000) in a review study mentions three factors that impact teachers' continued use of ICT: institution, resources and the teacher. Ely (1999) formulated eight conditions for the implementation of an educational innovation. This study related Mumtaz'(2000) factors to Ely's (1999) conditions for change model to examine the potential of beginning teachers' transfer of the ICT-enhanced activity based activities in their work places.

Table 1

Relationship between Mumtaz and Ely's conditions of transfer

\begin{tabular}{ll}
\hline Mumtaz & Ely \\
\hline Teachers & $\begin{array}{l}\text { Dissatisfaction with the status quo, sufficient knowledge and skills, } \\
\text { participation }\end{array}$ \\
Resources & Availability of resources, availability of time \\
Institutions & Rewards or incentives, commitment and leadership \\
\hline
\end{tabular}

In the study we applied Ely's conditions (slightly adapted) to postulate the other two components of Baldwin and Ford's (1988) model of factors influencing transfer. In particular the categorisation applied to: characteristics of the learners or trainees (Dissatisfaction with the status quo, sufficient knowledge and skills, commitment and availability of time) and work environment characteristics (Availability of resources, participation, Rewards or incentives and school culture). The two factors are further discussed in the following section.

\section{Characteristics of the learner}

Dissatisfaction with the status quo

The views that teachers hold about teaching, learning and ICT itself form an important foundation stone as to whether a teacher may use ICT-based innovations such as ICT-enhanced activity-based learning activities (ICT-ABL), in their practices. For example, teachers who hold strong views about collaborative learning tend to familiarise themselves with the idea of ICT integration, explore the potential of ICT to develop their knowledge base and reflect upon their own pedagogical practices (Bate, 2010). Teachers with this orientation may see students' engaging ICT as an intellectual partnership in which ICT is used as a cognitive tool (Jonassen, 2002) to extend students' learning and creativity. Other teachers may hold views about learning that emphasise the importance of the teacher as an efficient means of distributing knowledge. In these circumstances it is likely that ICT is equated with productivity (Maddux, LaMont Johnson \& Willis, 2001), as an opportunity to complement or amplify existing teaching approaches (Hughes, Thomas \& Scharber, 2006), or simply as a reward for early finishers. In this study, the assumption of transfer of learning of ICT-ABL is that beginning teachers are not satisfied with existing teaching approaches and see a need to change these towards approaches that support students' active learning.

Sufficient knowledge and skills

In order to make an implementation succeed, Ely (1999) indicated that the people who will ultimately use the innovation must possess sufficient knowledge and skills to do the job. This is especially the case when the innovation involves the use of a certain tool or a technique. Without enough preparation to use the tool or technique, the innovation will die out rapidly. According to Webb and Cox (2004), one of the reasons for the unenthusiastic response to ICT-based innovation amongst teachers might be that technological knowledge and skills are either absent or lacking in the processes that underpin teachers' planning. This idea has recently been developed by Harris, Mishra and Koehler (2009), who propose that there is a tendency for teachers not to synergise their content and pedagogical knowledge with their technological knowledge, and that this can result in mundane ways in which ICT-based innovations are implemented in the classroom. In this study, the beginning teachers who were implementers of the ICT$\mathrm{ABL}$ have been involved in professional development to learn technology by collaborative design to design and enact ICT-ABL. Knowledge and skills acquired during their professional development will reflect in the way beginning teachers currently enact their lessons, which was the reason to examine whether sufficient knowledge and skill about the innovation are a necessary factor for beginning teachers' transfer of ICT-ABL. 


\section{Commitment}

Since ICT-ABL design and use take a great deal of endeavor and time, the people involved in its usage need to make a major commitment in terms of effort and time. Thus commitment of the teacher is an essential ingredient to the successful implementation of an educational innovation. Riel and Becker (2008) indicated that teachers who have strong commitments to their pupils' learning and their own professional learning will evidently integrate ICT-based innovations within their teaching. In this study beginning teachers' commitment was measured by their dedication to their students' learning, in particular through ICT-ABL, and to their own development as teachers. It is expected that if beginning teachers are strongly committed to the innovation, the amount of knowledge transfer and teachers' willingness to use ICT-ABL for improving their students' learning will increase.

\section{Availability of time}

The adoption of an innovation takes time. As Ely (1999) explained, implementers of an innovation must have time to learn, adapt, integrate, and reflect on what they are doing. The adoption of the innovation does not necessarily bring forth the change (Fullan, 2007). It needs time for the people to understand the innovation and develop the abilities to adapt the innovation. Inadequate or insufficient time is recognised as a barrier to implementation of technology in higher education (Ebersole \& Vorndam 2003). Beginning teachers need time to practice their designed ICT-enhanced activity-based learning (ICT-ABL) lessons before enacting them in real classroom situations. In the study, availability of time refers to beginning teachers' willingness to devote time in developing their skills and abilities on how to use ICT-ABL before actual teaching; availability of time to practice during pre-lesson preparations is likely to influence beginning teachers' transfer of ICT-ABL.

\section{School environment characteristics}

\section{Availability of resources}

According to Mumtaz (2000), limited resources within schools are a great impediment to the take-up of technology. For instance, lack of computers and software in the classroom can seriously limit transfer of beginning teachers ICT-ABL. Studies have shown that only a small proportion of the African population has access to computers (Murphy, Anzalone, Bosch \& Moulton, 2002) and 4\% has access to the Internet (Resta \& Laferrière, 2008). Aguti and Fraser (2006) reiterated that lack of ready access to technologies by teachers is a key barrier to technology integration in most developing countries. Other researchers (Snoeyink \& Ertmer, 2002; Benson \& Palaskas, 2006) have identified resources as an important part of implementation of an innovation. In the study, adequate resources refer to the amount of resources currently available and accessible to the beginning teachers to successfully enact ICT-ABL lessons.

\section{Reward or incentives}

People need to be encouraged in their performance of innovation or use of innovations. Extrinsic or intrinsic rewards can add some value to the innovation, and thus, promote its implementation. These rewards can vary significantly from user to user. Additionally, the innovation itself may be perceived as a reward or the anticipated outcomes from the use of the innovation and may serve as incentives (Ely 1990, 1999). Stockdill and Morehouse (1992) identified rewards as a significant factor in "organizational capacity" (p. 57). Burkman (1987) discusses the use of rewards as part of "moral support" during implementation (p. 450). In this study, the existence of incentives or rewards provided by school management is presumed to motivate beginning teachers' use of ICT-ABL to foster their students' learning and was the reason to examine whether incentive is a necessary factor for beginning teachers' transfer of learning.

\section{Participation}

Participants in the implementation should be encouraged to be involved in decision-making. Participation may take the form of user group representatives if it is difficult to get feedback from all potential users (Ely 1990, 1999). Varkking (1995) states "participation in the design phase is in fact the first step of implementation" (p. 35). Participation was defined to include beginning teachers' involvement in decision making with regards to decisions that relate to the planning and design of the innovation in the school setting either through working committees or general staff meetings. With the opportunities to communicate their ideas and opinions, beginning teachers learning technology by design could contribute to their sense of the ownership of ICT-ABL in their school. 


\section{School Culture}

Another characteristic emerging from the literature regarding ICT integration is "school culture" (e.g., Tearle, 2003; Bate 2010), which can be defined as "the basic assumptions, norms and values, and cultural artifacts that are shared by school members" (Maslowski, 2001, p. 8-9). According to Bate (2010), a school's culture establishes the conditions for ICT practices in schools or at the level of organisations. These meanings and perceptions can be linked to the "readiness" of a school to adopt the planned change (Tearle 2003), as well as to teachers' actual take-up of ICT (Bennett, Crawford, Levačić, Glover \& Earley, 2000). In the present study, three underlying aspects of school culture were considered to assist (or hinder) beginning teachers' use of ICT-ABL lesson enactment: "School resistant to change" (Mumtaz, 2000), "importance of leadership in managing ICT, providing support and encouragement to users, as well as role modeling use of the innovation" (McGarr \& Kearney, 2009) and "provision of training opportunities" (Galanouli, Murphy \& Gardner, 2004). This study advocates that a favourable school culture will promote beginning teachers to successfully enact ICT-ABL in their schools.

The literature review has shown the importance of factors relating to learner characteristics, existing school environment characteristics and characteristics of a professional development program influencing transfer directly or indirectly. This study will seek to attain an understanding of the extent to which beginning teachers' transfer of learning of ICT-ABL in their teaching practice is influenced by these factors.

\section{Research Questions}

The study examined the extent to which beginning teachers were able to transfer knowledge and skills about designing and enacting ICT-enhanced activity-based learning activities (ICT-ABL) gained in the professional development program. The main research question that guided the study was: To what extent is beginning teachers' transfer of learning of ICT- ABL in their teaching practice influenced by learner characteristics, characteristics of the professional development program, and the characteristics of the school environment? The following sub-research questions were formulated to answer the main research question.

1. To what extent is beginning teachers' transfer of learning of ICT-ABL influenced by their perceptions of the professional development program ('learning technology by collaborative design').

2. To what extent is beginning teachers' transfer of learning of ICT-ABL influenced by perceptions of their learner characteristics?

3. To what extent is beginning teachers' transfer of learning of ICT-ABL influenced by perceptions about their school environment. Thus the study hypothesized transfer of ICT-ABL (ICT-ABL transfer $_{\text {) }}$ (dependent variables) as a function of the independent variables: learner characteristics (LEC), school environment characteristics (SEC) and characteristics of the professional development ( $\mathrm{LTCD}_{\text {perceptions }}$ ) as were reported by the beginning teachers. Transfer of learning was reported in beginning teachers' actual use and observed enactment of the ICT-ABL.

The study employed a mixed method research design (Creswell, Plano Clark, Gutmann \& Hanson, 2003) to help clarify and illustrate results from one method with the use of another method.

\section{Method}

\section{Participants}

One hundred (66 male, 34 female) beginning mathematics teachers were involved in the transfer study. The beginning teachers had participated in a professional development program during their final year at the teacher education program at the University of Cape Coast (UCC) to design and enact ICT-enhanced activity based learning for the first time. These teachers were currently pursuing their careers as mathematics teachers in various senior high schools. All 100 participants responded and completed a questionnaire survey that was administered through their emails. A random sample of 20 participants was interviewed and 6 of them were voluntarily observed to provide an authentic depiction of the way in which beginning teachers used ICT-ABL in their naturalistic classroom. 


\section{Instruments}

Three different instruments were used in the study. The questionnaire was used to assess beginning teachers' perceptions regarding the extent to which they used ICT-ABL and factors influencing their actual use; interview data provided in-depth elaborations for data collected through the questionnaire. The observation data provided information in which beginning teachers demonstrated actual use or transfer of ICT-ABL, as well as a record of prevailing factor in the schools.

\section{Questionnaire}

The questionnaire was developed based on instruments developed by Surry \& Ensminger (2004) and Zhu \& Engels (in press). It included teachers' perception about LTCD (5 items; Cronbach's $\alpha=0.89$ ) and actual use of ICT-ABL ( 5 items, Cronbach's $\alpha=0.78$ ). A five point Likert scale was used for teachers, use (where 5 = always, $4=$ often, 3 = sometimes, 2 = hardly, $1=$ never) (see Table 2 ) and teachers' perception $(1=$ strongly disagree, $5=$ strongly agree)(see Table 4$)$. The questionnaire also contained 30 statements $(1=$ strongly disagree, $5=$ strongly agree) representing beginning teachers' reported learner and school environment characteristics. The items could be classified under 8 sub-scales: availability of resources (Cronbach's $\alpha=0.79$ ), availability of time (Cronbach's $\alpha=0.80)$, commitment (Cronbach's $\alpha=$ 0.79 ), participation (Cronbach's $\alpha=0.69$ ), rewards or incentives (Cronbach's $\alpha=0.73$ ), school cultures (Cronbach's $\alpha=0.74$ ), knowledge and skill (Cronbach's $\alpha=0.81$ ) and dissatisfaction with status quo (Cronbach's $\alpha=0.77$ ).

\section{Teacher interview}

To explore the teachers' use of the ICT-ABL in their specific settings, semi-structured interviews were conducted. The following coding schemes were generated: value of the ICT-ABL, support for ICT-ABL implementation, hindrances to the ICT-ABL, and suggestions for effective ICT-ABL use.

\section{Observation checklist}

An observation checklist developed by the researcher was used to help focus and standardise observations. During visits to schools, the researcher used the observation checklist to assess six beginning teachers' actual use of the ICT-ABL. Table 3 shows the assessment for the teachers' usage levels of ICT-ABL. Data were also collected on the infrastructure and equipment that was available to the teachers who were being observed.

\section{Data analysis}

To analyse the quantitative data descriptive statistics, hierarchical cluster analysis, and regression analysis were conducted in SPSS. Effect size was calculated using Cohen's $d$ (Cohen, 1988). Cohen (1988) provided tentative benchmarks for the interpretation of effect sizes. He considers $d=0.2$ a small, $d=0.5$ a medium and $d=0.8$ a large effect size. The interviews were transcribed and coded using Atlas-ti. Two independent raters: the researcher and an expert with ample experience in the use of technology in teaching mathematics coded the interview data. The interrater reliability (Cohen's $\kappa)$ was $\kappa=0.90$.

\section{Results}

\section{Transfer of learning of ICT-ABL in beginning teachers' teaching practices: Beginners' teachers reported use of ICT-ABL}

A major question dealt with in the study was whether beginning teachers were able to transfer their knowledge and skill in enacting ICT-ABL in the way they currently enact their lessons and teaching practices. Table 2 presents the results of their reported use of ICT-ABL. Beginning teachers reported being able to transfer various aspects: use of teamwork among their students $(M=4.53, S D=0.489)$, use of lesson notes in guiding lessons $(M=4.63, S D=0.489)$ and use of activity-based pedagogical approach $(M=4.50, S D=0.50)$ during instructions while other aspects: use of "interactive demonstration" of spreadsheet techniques $(M=3.06, S D=0.653)$ and spreadsheet techniques to support mathematical concepts formation $(M=3.18, S D=0.599)$ appeared to be a challenge. Lack of ICT infrastructure might have been the strongest barrier constraining the teachers in their transfer; successful transfer of ICT-ABL requires ICT facilities. Beginning teachers explained this in their interview data. Two of them indicated: 
In my school, there is only one computer lab, which is used for teaching basic ICT for all the students from year 1 to year 4 . And the only projector in the school is used by the ICT teachers. (T14)

...but the major problem that hinder my use of the ICT-ABL has been lack of resources. There is no mathematics lab and the computer lab is used purposely for ICT teaching. The projection devices are used mainly for entertainment. T11)

Table 2

Beginning teachers' reported use of ICT-ABL $(N=100)$

\begin{tabular}{llc}
\hline Components & Mean & SD \\
\hline Activity-driven pedagogical approach (through worksheet) to support student & 4.50 & 0.500 \\
learning & & \\
Spreadsheet techniques to support mathematical concepts formation & 3.18 & 0.599 \\
Use of teamwork among students & 4.53 & 0.489 \\
Use of "interactive demonstration" of spreadsheet techniques in class & 3.06 & 0.653 \\
Use of lesson plan to guide lesson implementation & 4.63 & 0.489 \\
\hline
\end{tabular}

5 = always, $4=$ often, $3=$ sometimes, $2=$ hardly, $1=$ never

\section{Beginners' teachers' observed enactment of ICT-ABL}

Of the 6 beginning teachers, Felix, Joel, Mark, Gifty, Rene and Joe (pseudonyms used) who were observed, two (Mark \& Gifty) were from deprived ICT environments (without any ICT infrastructure whatsoever); the other four were situated in modest ICT settings (with a minimum of one computer lab with at least 40 computers). Mark had just gained appointment in a regional secondary school. The school itself was remote, comprising of a largely Indigenous population. In his lesson, Mark used components of the ICT-ABL (activities on a worksheet, students working in teams). He sees himself as one of the leaders in the school in terms of his ICT knowledge and skills in teaching, but exhibited frustration with the lack of ICT and support. Gifty, who found herself in a similar environment as Mark, used lesson plans to guide her lesson, in which students worked in teams using the worksheet to do various activities but did not use ICT as an instructional tool. She expressed similar frustrations in what she termed as poor leadership in supporting ICT-ABL and remarked on becoming somewhat de-skilled because of her lack of access to ICT facilities. Felix, Rene, Joel and Ike had some kind of ICT infrastructure in their school but had struggled when accessing them for use in their classrooms. For example, Rene conducted her lesson without any computer available to her (nor her students) in the classroom. She emphasised the possibility of having access to the computer lab once a week, but was hampered by what she sees as an apathetic school culture, in which timetabling was strictly adhered to leaving little or no room for changes. Felix admitted having his own laptop computer that he could use in class but explained that with the current class size of forty-five students, it was impossible to use the computer meaningfully for any student-directed activity without any projection device. Joel and Ike on the other hand were able to implement all components of ICT-ABL for teaching their lessons, yet were not without struggles. In observing Joel, he used his own laptop to enact his lesson (by rotating groups of students around his computer) to explore the potential of spreadsheets, giving students' an opportunity to discover mathematics concepts and perform authentic tasks because he did not have access to a projector. Ike's students also turned up in groups around his computer but had a difficult time in his lesson because the class size was large, with 50 students. Table 3 shows the ICT-ABL components that the teachers used as were assessed by the researcher. 
Table 3

Observation of beginning teachers' use of the ICT-ABL $(n=6)$

\begin{tabular}{|c|c|c|c|c|c|c|}
\hline ICT-ABL components & Felix & Joel & Mark & Gifty & Rene & Ike \\
\hline $\begin{array}{l}\text { Activity-driven pedagogical approach to } \\
\text { support student }\end{array}$ & $\boldsymbol{V}$ & $\checkmark$ & $\boldsymbol{\sim}$ & $\checkmark$ & $\boldsymbol{V}$ & $\checkmark$ \\
\hline $\begin{array}{l}\text { Spreadsheet techniques to support } \\
\text { mathematical concepts formation }\end{array}$ & & $\boldsymbol{\nu}$ & & & & $\checkmark$ \\
\hline Use of teamwork among students & $\boldsymbol{\nu}$ & $\boldsymbol{\nu}$ & $\boldsymbol{\sim}$ & $\boldsymbol{V}$ & $\boldsymbol{}$ & $\checkmark$ \\
\hline Use of "interactive demonstration" & & $\checkmark$ & & & & $\boldsymbol{V}$ \\
\hline $\begin{array}{l}\text { Use of lesson plan to guide lesson } \\
\text { implementation }\end{array}$ & $\checkmark$ & $\checkmark$ & & $\checkmark$ & $\boldsymbol{\sim}$ & $\checkmark$ \\
\hline
\end{tabular}

\section{Factors influencing beginning teachers' transfer of learning of ICT-ABL}

Beginning teachers' perceptions of "Learning technology by collaborative design".

The beginning teachers in the study reported their perceptions about continued use of LTCD within the existing support structures in their school settings. The results showed positive high perceptions of teachers to learn technology by collaborative design as reported in Table 4.

Table 4

Beginning teachers' perceptions of LCTD $(N=100)$

\begin{tabular}{lll}
\hline Learning technology by collaborative design (LTCD) & $M$ & $S D$ \\
\hline Use of design teams to develop worksheets, spreadsheet techniques and lesson & 4.63 & 0.489 \\
plans & 4.75 & 0.439 \\
Use (importance) of exemplary materials (or resources from internet) & 4.88 & 0.328 \\
Support from the facilitator is helpful in the design process & 0.010 \\
Learning by doing (by exploring spreadsheet techniques activities) is a useful & 4.96 & \\
strategy in learning to design the spreadsheet-supported activity based & & \\
mathematics lessons & 4.98 & 0.004 \\
Enactment of lesson plans in microteaching or classroom settings & & \\
\hline (5= strongly agree, 1 strongly disagree) & &
\end{tabular}

The overall perception of LTCD $(M=4.85, S D=0.191)$ was highly valued by the beginning teachers, indicating that approximately six, eighteen or twenty-eight months after the professional development program the beginning teachers held strong positive pedagogical views about the professional development program 'learning technology by collaborative design'(LTCD). It was evident that the preparatory program had impacted on beginning teachers' views about LTCD and could be central in influencing their use of ICT-ABL in their professions or teaching practice.

\section{Beginning teachers' reported learner characteristics (LEC) and School environmental characteristics (SEC)}

Based on the hierarchical cluster analysis, the eight factors that promoted or hindered transfer (as reported by the teachers) were distributed in two clusters (see Figure 1). They were: learner characteristics (LEC) (personal factors related to teachers' knowledge and skill, commitment, availability of time and their dissatisfaction with the status quo which influence transfer) as cluster 1 and school environment characteristics (SEC) (school- related factors: school culture, availability of resources, rewards and incentives and participation in decision making which directly or indirectly influence transfer) as cluster 2. 


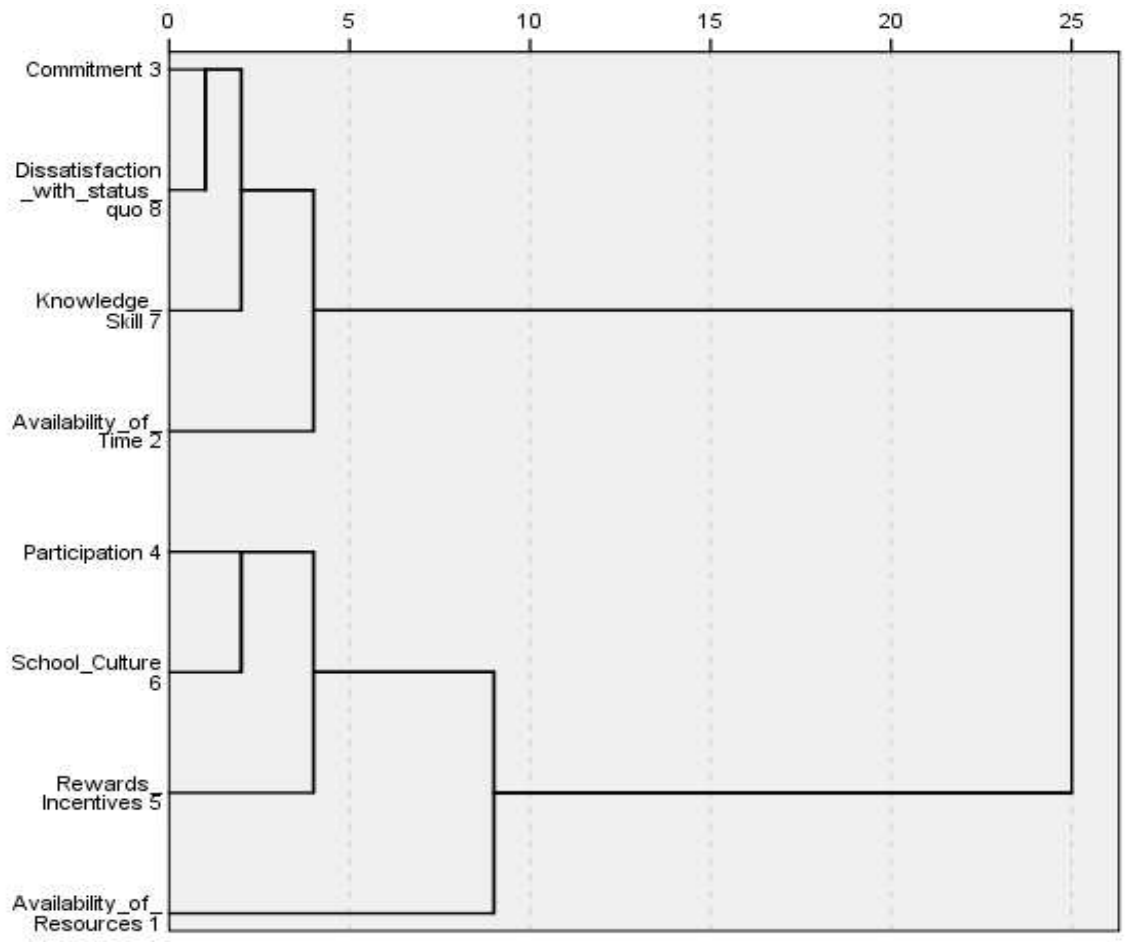

Figure 1. Hierarchical clustering dendrogram of conditions using Average Linkage

Cronbach's alpha for the items in each cluster: .71(LEC) and .79 (SEC) were acceptable according to guidelines provided by DeVellis (1991). Beginning teachers tended to agree strongly to LEC cluster $(M=$ $4.20, S D=0.451)$, while they tend to disagree on the SEC cluster $(M=2.48, S D=0.155)$ indicating prevailing unfavourable school environment characteristics. In addition, the standard deviation for SEC is very small, indicating that the beginning teachers did not differ much in their opinion about the SEC cluster. The differences between the mean scores of the clusters were statistically significant $(p<0.001)$ for both scale scores, with a large effect size $(d=3.17)$. Table 5 shows the ranking of the factors with their means and standard deviations as were reported by beginning teachers for each factor.

Table 5

Mean score and standard deviations for factors influencing beginning teachers transfer of learning $(N=100)$

\begin{tabular}{lcc}
\hline Conditions & $M$ & $S D$ \\
\hline LEC & & \\
Skills and knowledge & 4.57 & .355 \\
Dissatisfaction with status quo & 4.48 & .383 \\
Commitment & 4.21 & .287 \\
Availability of Time & 3.75 & .562 \\
SEC & & \\
Rewards and Incentives & 3.17 & .137 \\
Participation & 3.02 & .103 \\
School Culture & 2.05 & .292 \\
Resources & 1.71 & .011 \\
\hline
\end{tabular}

Overall, knowledge and skills appeared to be the most valued factor followed by dissatisfaction with status quo. This seems to suggest that while the program might have impacted on knowledge and skill acquisition, beginning teachers were dissatisfied with existing methods of instruction and reiterated the need for a change. Table 5 also indicates that the teachers' commitment and availability of time were important factors that contributed to their use of the ICT-enhanced activity-based activities. On the other hand, existing conditions regarding ICT resources, school culture and teachers participation in decision- 
making appeared unfavorable and perhaps do not foster teachers' use of ICT-ABL. Lack of ICT resources and unfavorable school cultures especially were perceived as barriers to teachers' use of ICTABL. The teachers expressed their frustrations regarding these observations in the interview data in various ways:

Very few resources are available. Apart from the problem with ICT resources, there are also problems with timetabling. The period for teaching mathematics with ICT is very short whereas the workload is huge. (T03)

The leadership of the school does not afford a high enough priority to ICT planning and implementation. As far as leadership goes in the school, use of ICT-based innovation is not a large focus so there is little I can do. (T10)

My school did not organize any in-service training and timetable structure does not allow precise considerations to access computer labs for teaching. (T04)

\section{Predicting teachers' transfer of ICT-ABL in their teaching practices}

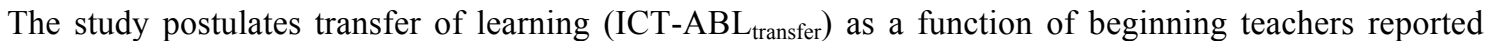
learner characteristics (LEC), their existing (unfavorable) school environment characteristics (SEC) and their perceptions $\left(\mathrm{LTCD}_{\text {perceptions }}\right)$ about the professional development program. The exact weights of each parameter and relations between them were determined empirically (Table 6). The result indicates that the $R^{2}$ for transfer of learning regarding use of ICT-ABL predicted from the teachers' perception about LTCD showed that $19 \%$ of the variance in the transfer of ICT-ABL in teaching practices was found to be attributable to the LTCD innovation characteristics. The $F$ test $(F=(1,98)=6.07, p<0.01)$ associated with the independent variable ( $\mathrm{LTCD}_{\text {perceptions }}$ ) was significant, indicating that the independent variable

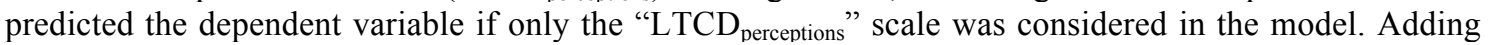
the LEC measure increased the predictability for ICT-ABL $\mathrm{L}_{\text {transfer }}$ from approximately $19 \%$ to approximately $21 \%$. Although the LEC measure did not appear as strong as the $\mathrm{LTCD}_{\text {perceptions }}$ measure, $R^{2}$ change $=.02$, the $\mathrm{F}$ test $F(2,97)=3.06$ and $p=0.047$ were significant (at 0.05$)$ for the model. The existing unfavorable SEC measure when added, increased the predictability significantly, $R^{2}$ change $=.10$, $F=(3,96)=4.69$ with $\mathrm{p}<.01$.

Table 6

Coefficients of Predictors: School environment characteristics (SEC), learner characteristics (LEC) and perception about the ICT-enhanced activity-based activities $(N=100)$.

\begin{tabular}{|c|c|c|c|c|c|}
\hline$I C T-A B L_{\text {transfer }}$ & $R$ & $R$-square & $F($ Sig) & $\begin{array}{c}\text { Standardized } \\
\text { coefficients }\end{array}$ & Sig \\
\hline Impact of LTCD $_{\text {perceptions }}$ & 0.44 & 0.19 & $6.07(0.001)^{* *}$ & $0.27(p)$ & $0.002 * *$ \\
\hline Impact of LTCD perceptions and LEC & 0.46 & 0.21 & $3.06(0.047)^{*}$ & $\begin{array}{l}0.25(p) \\
0.08(t)\end{array}$ & $\begin{array}{l}0.003 * * \\
0.033 *\end{array}$ \\
\hline Impact of LTCD perceptions, LEC and SEC & 0.56 & 0.31 & $4.69(0.001)^{* *}$ & $\begin{array}{c}0.26(p) \\
0.09(t) \\
-0.13(s)\end{array}$ & $\begin{array}{l}0.002 * * \\
0.036 * \\
0.011\end{array}$ \\
\hline
\end{tabular}

Note: $* p<0.05 ; * * p<0.01 ; p=$ perception of beginning teachers, $t=T E C, s=S E C$

\section{Discussion}

This study examined the extent to which beginning teachers were able to transfer their knowledge and skills to utilise an ICT-enhanced activity-based learning which they learnt through "Learning technology by design" in their final year of their beginning preparation education program. In particular, the study sought to attain an understanding of how beginning teachers reported learner characteristics, existing school environment characteristics and characteristics of the ICT-enhanced activity-based innovation itself, influenced transfer of learning in their professional and teaching practice.

Results of the study showed that beginning teachers continued to employ aspects of the ICT-enhanced activity-based learning in their professional and teaching practice within the existing support structures of their respective schools. This was demonstrated through beginning teachers' use of teamwork among their 
students, use of lesson notes in guiding lessons and use of activity-based pedagogical approaches. "Interactive demonstrations using spreadsheets" and the use of "spreadsheet techniques" as instructional tools to support mathematical concepts formation on the other hand appeared to be an ongoing challenge. The most influential factor reported, which seemed to facilitate teachers' transfer and use of the ICTenhanced activity-based learning activities, was the strong pedagogical views about the professional development program that beginning teachers still hold several months after finishing their teacher education preparatory program. Results from the regression analysis also showed that a significant amount of variance attributed to the teachers' learner characteristics explained differences in the level of transfer of the ICT-enhanced activity-based learning innovation. The most critical learner characteristics reported was beginning teachers' knowledge and skills acquired. This is an indication of how well the preparatory program contributed to teachers' professional learning. The second most critical condition, teachers' dissatisfaction with the status quo, shows that the teachers saw the need to change existing teaching approaches towards approaches which support ICT-enhanced activity-based learning activities. Furthermore, the teachers' commitment factor was also reported by beginning teachers to have promoted transfer of learning. Riel and Becker (2008) indicated that teachers who are motivated and have strong commitments to their pupils' learning and their own professional development evidently integrate ICTbased innovations, such as ICT-enhanced activity-based learning more easily during their teaching. Conditions regarding existing school-related factors did not seem to differ much across schools and though were perceived as unfavorable or a hindrance, the regression analysis indicated that they were significant in determining transfer of learning of the ICT-enhanced activity-based activities. This is in agreement with studies (Bate, 2010; Benson \& Palaskas, 2006; Snoeyink \& Ertmer, 2002; Mumtaz, 2000) conducted in the western world that identified school-related factors as important in implementing ICTbased innovations.

The lesson observations confirmed that participants faced a complex mix of school-related constraints that when combined, contributed to a lack of creativity in using certain components of the ICT-enhanced activity-based learning activities. Particularly, lack of access to the ICT infrastructure and an unenthusiastic school culture were pronounced. In most schools, ICT facilities were not accessible in classrooms. This impacted on the creative use of ICT-enhanced activity-based learning, particularly in large classes. Often, even the most enthusiastic teachers could do little more than rotate students through teachers' personal computers in their classrooms. In situations where a centralised computer laboratory was available, participants struggled to gain appropriate and timely access. This state of affairs is also common in the literature (Groff \& Mouza, 2008) and also supports the contention that the specific positioning of computers in the school can foster or hinder ICT-based innovation use in teaching and learning (Tondeur, Valcke, \& van Braak, 2008).

\section{Practical implications}

The study showed that a significant amount of variation in the transfer of learning and the utilisation of ICT-enhanced activity-based learning activities was attributed to a range of factors across individual beginning teachers' learner characteristics, characteristics of the ICT-enhanced activity-based learning innovation and existing school environment characteristics. The findings reported here therefore highlight areas that require further attention to move the goal of transforming teaching and learning through ICTenhanced activity-based innovations beyond rhetoric.

Parent Teachers' Association, School Management and Boards must join forces and put priority on the provision of ICT facilities in Ghanaian schools (e.g. mathematics laboratories, computers and projection devices in classrooms) to facilitate and increase access to ICT of teachers. Easy access to ICT facilities will certainly contribute to teachers' use of ICT innovations in schools.

The study found that transfer of ICT-enhanced activity-based learning from the teacher preparation program to the real classroom setting was problematic especially with respect to unfavorable school environment. Consequently, there is an urgent need to resolve difficult dilemmas in the terrain of ICT and innovative school culture such as: school-based in-service education opportunities, flexibility of classroom timetable and willingness to change existing traditional approaches. The study therefore recommends that the Ghana Education Service (GES) strengthen and enforce policies regarding the practical use of ICT for educational practices in the curriculum. A clear articulation of policy within the framework of the teacher education institution and GES could ensure better grounding of learning and 
transfer of ICT-enhanced activity-based learning in education in Ghana.

Another practice that could assist in the transition from the teacher preparation program to the schools is to advocate for a collaborative program between providers of beginning education and schools. In this way principals and school leaders will be supported to provide the type of pedagogical leadership in ICT integration that will inspire new teachers to push the boundaries of using ICT-enhanced activity-based learning innovation. Apart from providing support for school leadership, such a "symbiotic" partnership will help in addressing the realities of specific teaching contexts; and provide a forum for school- and preservice providers to think together about the learning needs and challenges of beginning teachers' use of ICT in their practices and teaching professions.

The study also unveiled that lack of support in the face of a wide range of responsibilities was a compelling challenge for beginning teachers' use of the ICT-enhanced activity-based learning activities in their practice. For instance, while ensuring that the curriculum covered was particularly important to the beginning teachers in this study, questions like: how teachers could balance the demands of a crowded curriculum by providing students with opportunities to explore mathematical concepts using ICT in ways that embrace the principles of lifelong learning and how effective models of ICT use that cut across curricula and timetable constraints could be addressed were some concerns raised by the beginning teachers. According to Feiman-Nemser (2001) these multiple challenges of teaching alone for the first time can discourage new teachers from trying ambitious pedagogies and that good induction support could keep novices from abandoning these approaches in favor of what they may perceive as safer, less complex activities. The study has implications consistent with this research and advocates for the introduction of induction program for beginning teachers in Ghana and similar contexts. Such a program will serve as a short-term support to ease new teachers' entry into the teaching profession and to help them cope with their first year on the job.

In conclusion, the study draws attention to the importance of transfer of learning, particularly with regards to the development and implementation of educational innovations in developing countries, in order to help lessen the gap between learning and sustained work performance, given that many innovations in this context are very vulnerable and fail to be transferred.

\section{References}

Aguti, J. N., \& Fraser, W. J. (2006). Integration of information communication technologies in the distance education programme, Makerere university, Uganda. Distance Education, 7(3 ), 89-104.

Agyei, D.D (2012). Preparation of Pre-service Teachers in Ghana to integrate Information and Communication Technology in teaching Mathematics. Enschede: University of Twente.

Agyei, D. D., \& Voogt, J. (2011). Exploring the potential of the Will Skill Tool model in Ghana: Predicting prospective and practicing teachers' use of technology. Computers\& Education., 56(1), 91100.

Baldwin, T. T., \& Ford, J. K. (1988). Transfer of training: A review and directions for future research. Personnel Psychology, 41, 63-105.

Bate, F. (2010). A bridge too far? Exploring beginning teachers' use of ICT in Australian schools. Australian Journal of Educational Technology, 26(27), 1042-1061.

Bennett, N., Crawford, M., Levačić, R., Glover, D., \& Earley, P. (2000). The reality of school development planning in the effective primary school: technicist or guiding plan? School Leadership and Management, 20, 333-351.

Benson, R., \& Palaskas, T. (2006). Introducing a new learning management system: An institutional case study. Australasian Journal of Educational Technology, 22(4), 548-567.

Burke, L. A., \& Hutchins, H. M. (2007). Training transfer: An integrative literature review. Human Resource Development Review, 6 (3), 263-296. doi: DOI: 10.1177/1534484307303035. 
Burkman, E. (Ed.). (1987). Factors affecting utilization: Foundations. Hillsdale, NJ: Lawrence Erlbaum.Cohen, J. (1988). Statistical Power Analysis for the Behavioral Sciences (2nd ed.). New Jersey: Lawrence Erlbaum Associates.

Creswell, J. W., Plano Clark, V. L., Gutmann, M., \& Hanson, W. (Eds.). (2003). Advanced mixed methods research designs. Thousand Oaks, CA: Sage.

DeVellis, R. F. (1991). Scale development. Newbury Park, CA: Sage.

Ebersole, S., \& Vorndam, M. (2003). Adoption of computer based instructional methodologies: A case study. International Journal of E-Learning, $2(2$ ), 15-20.

Ely, D. P. (1990). Conditions that facilitate the implementation of educational technology innovations. Journal of Research on Computing in Education, 23(2), 298-305.

Ely, D. P. (1999). Conditions that facilitate the implementation of educational technology innovations. Educational Technology, 39, 23-27.

Feiman-Nemser, S. (2001). From preparation to practice: Designing a continum to strengthen and sustain teaching. Reachers College Record, 103(6), 1013-1055.

Fullan, M. (2007).The new meaning of educational change (4th ed.). New York: Teachers College Press.

Galanouli, D., Murphy, C., \& Gardner, J. (2004). Teachers' perceptions of the effectiveness of ICTcompetence training. Computers \& Education, 43, 63-79.

Goldstein, I. L., \& Ford, J. K. (2002). Training in organizations. Belmont, CA: Wadsworth. Hall, G.E., Loucks, S.R., Rutherford, W.L., and Newlove, B.W. (1975). Levels of use of the innovation: a framework for analyzing innovation adoption. Journal of Teacher Education, 26(1), 52-56.

Groff, J., \& Mouza, C. (2008). A framework for addressing challenges to classroom technology use. AACE Journal, 16(1), 21-46.

Harris, J., Mishra, P., \& Koehler, A. M. (2009).Teachers' Technological Pedagogical Content Knowledge and learning activity types: Curriculum-based technology integration reframed. Research on Technology in Education, 41(4), 393-416.

Hughes, J., Thomas, R., \& Scharber, C. (2006). Assessing technology integration: The RAT -replacement, amplification, and transformation - framework. Paper presented at the Technology and Teacher Education Annual Conference.

Jonassen, D. (2002). Computers as mindtools for schools. New Jersey: Prentice-Hall Inc.

Koehler, M., \& Mishra, P. (2005). What happens when teachers design educational technology?The development of technological pedagogical content knowledge. Journal of Educational Computing Research, 32(2), 131-152.

Maddux, C., LaMont Johnson, D., \& Willis, J. (Ed.). (2001). Educational computing. Needham Heights, MA: Allyn \& Bacon.

Maslowski, R. (2001.) School culture and school performance: An explorative study into the organizational culture of secondary schools and their effects. Twente: UniversityPress.

McGarr, O., \& Kearney, G. (2009). The role of the teaching principal in promoting ICT use in small primary schools in Ireland. Technology, Pedagogy and Education, 18(1), 87-102.

Mumtaz, S. (2000). Factors affecting teachers' use of information and communications technology: A review of the literature. Information Technology for Teacher Education, 9(3), 319-342. 
Murphy, P., Anzalone, S., Bosch, A., \& Moulto, J. (2002). Enhancing learning opportunities in Africa: Distance education and information and communication technologies for learning. Africa region human development working paper series.

Resta, P., \& Laferrière, T. (2008). Issues and challenges related to digital equity. In J. Voogt, \& G. Knezek (Eds.), International handbook of information technology in primary and secondary education (pp.765-778). New York: Springer.

Riel, M., \& Becker, H. J. (2008). Characteristics of teacher leaders for Information and Communication Technology. In J. Voogt \& G. Knezek (Eds.). International handbook of information technology in primary and secondary education (pp. 397-417). New York: Springer.

Saks, A. M. (2002). So what is a good transfer of training estimate? A reply to Fitzpatrick. The IndustrialOrganizational Psychologist, 39, 29-30.

Snoeyink, R., \& Ertmer, P. A. (2002). Thrust into technology: how veteran teachers respond. Journal of Educational Technology Systems, 30(10), 85-111.

Stockdill, S. H., \& Morehouse, D. L. (1992). Critical factors in the successful adoption of technology: A checklist based on TDC findings. Educational Technology, 1, 57-58.

Surry, D. W., \& Ensminger, D. C. (2004). Development of implementation profile instrument. British Journal of Educational Technology, 34(4), 503-504.

Tearle, P. (2003). ICT implementation: What makes the difference? British Journal of educational Technology, 34, 567-583.

Tondeur, J., Valcke, M., \& van Braak, J. V. (2008). A multidimensional approach to determinants of computer use in primary education: Teacher and school characteristics. Journal of Computer Assisted Learning, 24(6), 494-506.

Varkking, W. J. (1995). The implementation game. Journal of Organizational Change Management 8 (3), 31-46.

Webb, M., \& Cox, M. (2004). A review of pedagogy rated to information and communications technology. Technology, Pedagogy and Education, 13(3), 235-286.

Yamnill, S., \& McLean, G. N. (200). Theories supporting transfer of training. Human ResourceDevelopment Quarterly, 12(2), 195-208.

Zhu, C., \& Engels, N. (2013). Organizational culture and instructional innovations in higher education: perceptions and reactions of teachers and students. Educational Management Administration \& Leadership. Doi: 10.1177/1741143213499253.(ISI/SSCI)

Corresponding author: Douglas D. Agyei, ddagyei@yahoo.com.

Australasian Journal of Educational Technology (C) 2014.

Please cite as: Agyei, D. D., \& Voogt, J. (2014). Examining factors affecting beginning teachers' transfer of learning of ICT-enhanced learning activities in their teaching practice. Australasian Journal of Educational Technology, 30(1), 92-105. 